\section{EREM 77/3}

Journal of Environmental Research, Engineering and Management Vol. 77 / No. 3 / 2021 pp. 23-31

DOI 10.5755/j01.erem.77.3.28438

\section{Solar Hybrid Hatching Machine Applying a Thermal Accumulator with a Reflective Array Method}

Received 2021/02

Accepted after revision 2021/08

\title{
Solar Hybrid Hatching Machine Applying a Thermal Accumulator with a Reflective Array Method
}

\author{
Budhy Setiawan*, Riska Nur Wakidah* \\ State Polytechnic of Malang
}

*Corresponding authors: stbuddy@yahoo.com, riska_nur@polinema.ac.id

In this research, a hybrid egg hatcher machine applied two types of energy for heating, namely solar thermal energy and an electric (fossil) heater. Solar energy was the main energy, and the electric heater was the secondary energy. This hybrid system was related to Indonesian geography, with high solar energy of an average of $5 \mathrm{kWh} / \mathrm{m}^{2} / \mathrm{day}$ in one year. Therefore, solar thermal energy storage will be effectively used in Indonesia to reduce fossil energy exploitation. The solar thermal energy was stored in an accumulator with a $4 \mathrm{~m}^{2}$ collector. The solar thermal accumulator was an insulated vessel with high reflectivity and insulation. The heat energy was stored and kept in some water bars. In maximizing absorption capability, the collector used a reflective array method that was operated by opening or closing the arrays. The arrays were controlled by an electronic controller, which compared the thermal energy inside with the energy of sunlight. The array's movement to charge the accumulator was done automatically by using the hysteresis switching method. The electric heater will be used only if the accumulator temperature is less than $40^{\circ} \mathrm{C}$. The capacity of the egg hatcher machine accumulator was 300 eggs. Raw data were collected using a data logger of DAQ (Data Acquisition Interface) DT9813 to determine and analyze the performance of system parameters. From the data collected, the solar thermal accumulator showed its capability for storing thermal energy up to $7.07 \mathrm{kWh}$. However, its average absorption efficiencies were $54-58 \%$ by direct solar and 60-70 \% by diffuse solar. Experiments verified the effectiveness of the designed accumulator. The experimental results showed that the electrical energy consumption was reduced up to $64 \%$.

Keywords: thermal accumulator, reflective array method, hatching machine. 


\section{Introduction}

In the current condition, $80 \%$ of electrical energy is produced by burning fossil fuels. This massive exploitation leads to the world's energy shortage and a threat to the environment (Ramli, 2015). The world's fossil reserves are decreasing (Syah, 2012; Setiawan, 2020); thus, renewable energy is one solution to overcome that problem. The utilization of free and long-lasting solar thermal energy is considered promising in providing electrical energy (Syah, 2012; Setiawan, 2018).

It has been reported that the average solar energy measured in tropical regions is $1 \mathrm{~kW} / \mathrm{m}^{2}$, and the average energy is $7 \mathrm{~kW}$ hours $/ \mathrm{m}^{2} /$ day (Ramli, 2015; Setiawan, 2018). By using current technologies, solar energy can be utilized as electrical power or can be stored. Liquid and dry materials are commonly used as media for storing solar energy.

A flat-plate collector is one of the technologies that use solar thermal energy storage, which is the basic idea of a solar thermal collector in the form of an oven like a box (Ramli, 2015). This technology has a high efficiency compared with solar cells, up to $80 \%$ energy conversion (Nasruddin, 2007). Solar cells are only capable of maximum converting $20 \%$ of solar energy (French, 1997). With this technology, the stored heat energy can be utilized as a dry heat accumulator system with a 60-70\% efficiency and a water accumulator with a $47 \%$ efficiency (Bhowmik, 2017; Setiawan, 2020).

Solar thermal energy storage is effectively used in Indonesia and other high-intensity countries to reduce fossil energy exploitation, which is related to Indonesia's geographical position in equatorial coordinates with high solar energy, an average of $5 \mathrm{kWh} / \mathrm{m}^{2} /$ day per year (Republika, 2014).

One technology that can directly utilize solar thermal energy without conversion is an egg hatch machine (Syah, 2012). The egg hatcher needs thermal energy for hatching, and almost all heat sources today use electrical energy. It would be wise to use an accumulator of solar thermal energy as a heat source for the egg hatcher. The use of solar thermal energy can also help to reduce the use of fossil energy. Therefore, an electrical energy reduction of up to 60\% can be expected (Syah, 2012).

\section{Modelling of the System}

A hybrid egg incubator machine has three main components: a collector and an accumulator unit, a regulator, and a hatcher, as seen in Fig. 1.

\section{The collector and accumulator unit}

The solar thermal accumulator is an insulated and high reflectivity vessel that can store and keep solar thermal energy with water as the media in galvanized bar vessels.

The accumulator is designed in such a way that solar energy and thermal energy do not leak out. On the inside of the accumulator, there are some layers to maintain stored energy: a $1 \mathrm{~mm}$ thick aluminium plate on the outer side and $4 \mathrm{~cm}$ thick Styrofoam wrapped with a reflector facing the server as an insulator.

Fig. 1. Hybrid egg incubator system

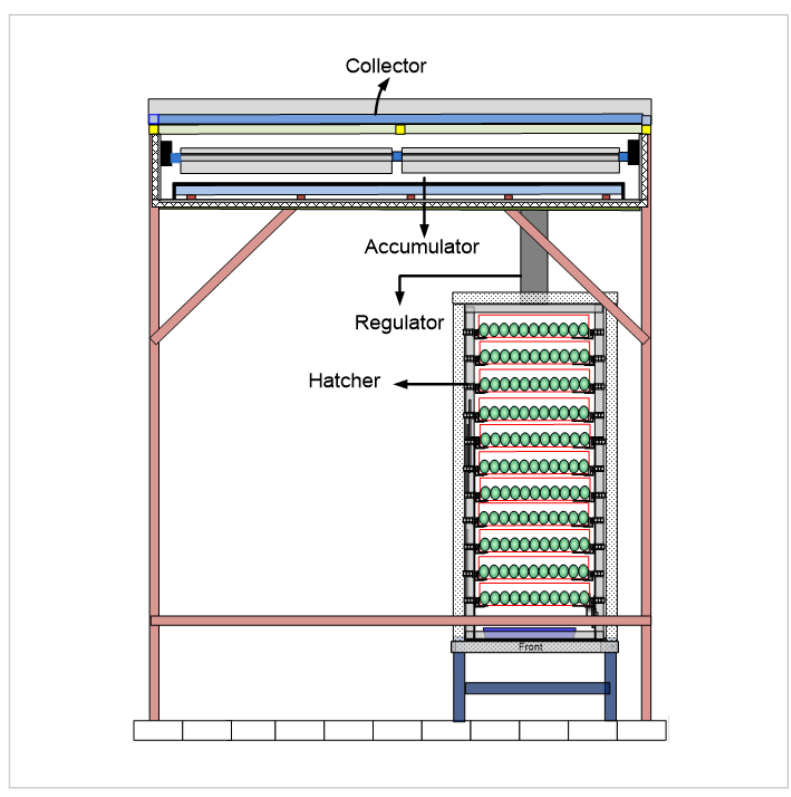

On the top of the accumulator, there is a vacuum glass of $5 \times 10^{-3} \mathrm{~m}$ thickness to pass solar energy into the accumulator. Bellow the glass, an array reflector made of stainless steel is controlled by an electronic controller with a linear mirror array control method. The array reflector will open when the external energy is greater than the inner, and the temperature inside is less than $100^{\circ} \mathrm{C}$, as shown in Fig. 3. The stainless-steel material 
was chosen because it reflects up to $78 \%$ (Setiawan, 2018). With those designs, the accumulator will be an absolute closed chamber capable of trapping heat inside. A piece of black fabric was added on the top of galvanizing bars to maximize the capture of solar thermal energy, as shown in Fig. 2.

Fig. 2. Accumulator from the left side

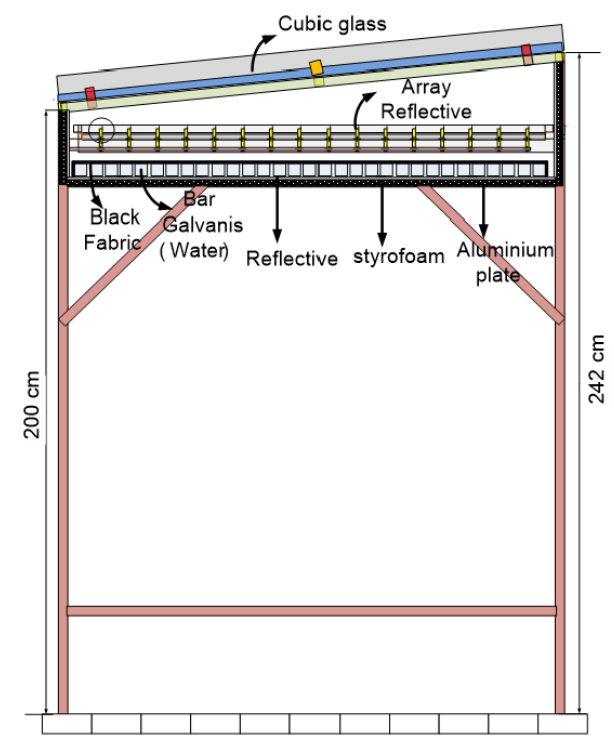

In this research, the accumulator had an outer length and width of $2 \mathrm{~m} \times 2 \mathrm{~m}$ and an inner length and width of 1.9 $\mathrm{cm} \times 1.9 \mathrm{~cm}$. In the center of the accumulator, there was a border as an array buffer with a width of $0.09 \mathrm{~m}$. Thus, the area that could capture solar energy was $3.14 \mathrm{~m}^{2}$.

Fig. 3. Control linear mirror array

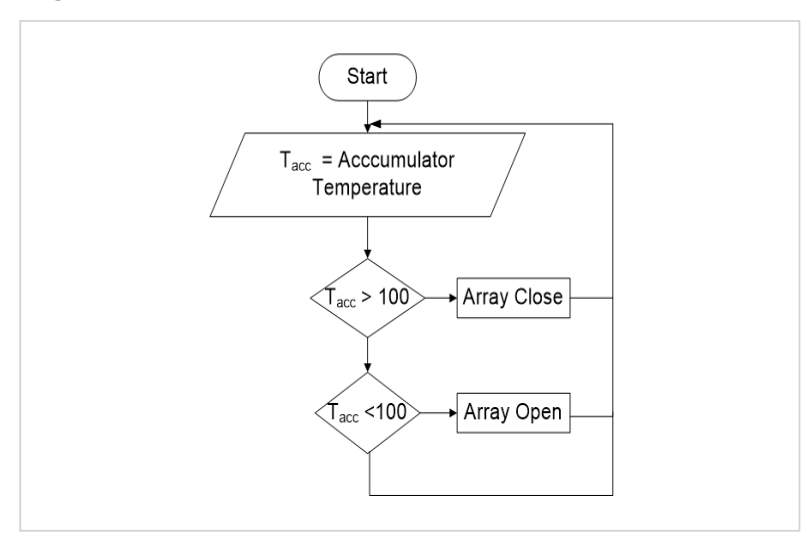

Water was chosen as a heat storage medium because it has a high specific heat capacity of $4.2 \mathrm{~kJ} / \mathrm{kg}^{\circ} \mathrm{C}$. Water was stored in 27 galvanized bars with a volume of 2.87 $\times 10^{-3} \mathrm{~m}^{3}$ each and four galvanized bars with a volume of $2.97 \times 10^{-3} \mathrm{~m}^{3}$ each. The total volume of storage media was $0.10156 \mathrm{~m}^{3}$ or equivalent to $101.56 \mathrm{~L}$. In addition to water mass, the galvanic mass also affected the energy storage capacity of the accumulator. The total galvanic mass in the accumulator was $48.8 \mathrm{~kg}$ with a galvanic specific heat capacity of $0.460 \mathrm{~kJ} / \mathrm{kg}^{\circ} \mathrm{C}$. Therefore, the storage capacity of the accumulator $\left(E_{\text {acc }}\right)$ was $29504.325 \mathrm{KJ}$ or $8.1 \mathrm{kWh}$. It could be calculated by entering the parameter values related to equation (1).

$$
E_{a c c}=(M w \cdot C w \cdot \Delta T)+(M g \cdot C g \cdot \Delta T)
$$

Where: $M_{w}$ - mass of water; $C_{w}$ - heat capacity of water; $M_{g}$ - mass of galvanized; $C_{g}$ - heat capacity of galvanized; $\Delta T-T_{2}-T_{1}$.

\section{The regulator}

The regulator is a medium used to decrease the high temperature in the accumulator to the required temperature of the incubator.

High-temperature accumulator regulation was implemented by the buck converter method. The high temperature of the accumulator $\left(40-100^{\circ} \mathrm{C}\right)$ was decreased and was maintained at a low temperature in the hatcher $\left(37.5^{\circ} \mathrm{C}\right)$.

Fig. 4. Heat regulator with the buck converter method

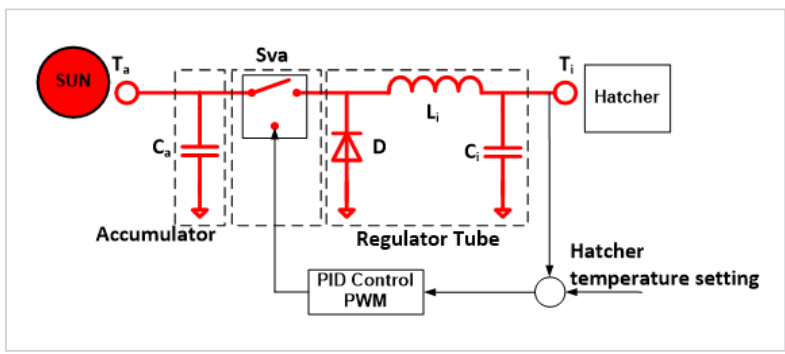

Fig. 4 shows the implementation of a buck converter circuit that is implemented for thermal energy, in addition to electrical energy. $\left(\mathrm{T}_{\mathrm{a}}\right)$ correlates with the heat temperature of the accumulator. The accumulator capacitor $\left(\mathrm{C}_{\mathrm{a}}\right)$ is correlated to the accumulator as a heat bank. Valve (Sva) functions as an opening and closing of the hot airflow 
from the accumulator to the hatcher and is held by the PID controller. In contrast, the diode (D), the inductor (Li), and the capacitor $(\mathrm{Ci})$ are models of the regulator tube. The regulator tube traps the flow of heat energy by balancing $\mathrm{L}_{i}$ and $\mathrm{C}_{i}$; therefore, the incubator output (Ti) will be obtained $\left(37-41^{\circ} \mathrm{C}\right)$ according to the setting.

\section{The hatcher}

In this research, the hatcher was designed with a capacity of 300 eggs.

The box hatcher was made with a length of $72 \mathrm{~cm}$, a width of $64 \mathrm{~cm}$, and $100 \mathrm{~cm}$ of height. The box was made of aluminium with a thickness of $0.8 \mathrm{~mm}$. In maintaining the hot temperature, a Styrofoam with a $5 \mathrm{~cm}$ thickness inside the body box was wrapped with a reflector materi$\mathrm{al}$, and the door was added with a rubber seal. The design of the hatcher is shown in Fig. 5.

Fig. 5. Incubator box design

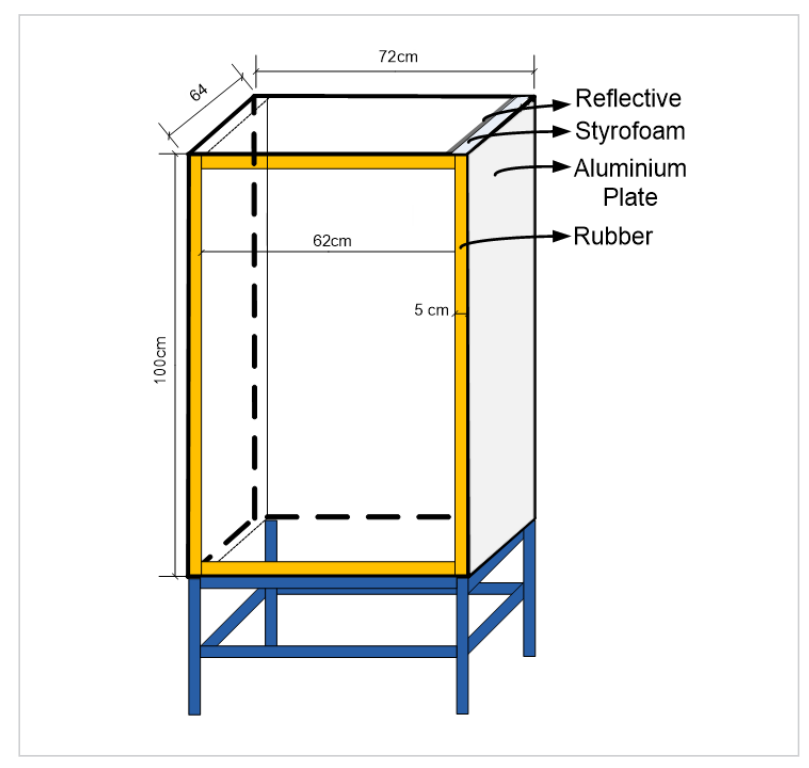

\section{Heat energy requirement to hatch 300 eggs}

The power requirement for 300 eggs was $60.6 \mathrm{~W}$. It can be calculated that a chicken egg required $0.202 \mathrm{~W}$ of power (Setiawan, 2017). Thus, the required heat energy $(\delta Q)$ was $60.6 \mathrm{~J}$.

In this research, 300 eggs were replaced with the air blown outside the hatcher through a DC fan of $0.0144 \mathrm{~m}^{2}$ wide. The energy which was blown out was the same as the energy requirement for 300 eggs. The blown energy can be calculated by equation (2) as follows:

$$
m_{a}=\frac{E_{e g g}}{C_{a} . \Delta T}
$$

Where: $m_{a}$ - mass of air; $E_{\text {egg }}$ - energy of egg; $C_{a}$ - heat capacity of air; $\Delta T-T_{2}-T_{1}$.

With the heat capacity of air $\left(C_{a}\right) 0.716 \mathrm{~kJ} / \mathrm{kg}{ }^{\circ} \mathrm{C}$, a minimum temperature of $25^{\circ} \mathrm{C}$, and a maximum temperature of $37.5^{\circ} \mathrm{C}$, the mass required to replace 300 eggs was $6.77 \mathrm{~g}$ or equal to $5.236 \times 10^{-3} \mathrm{~m}^{3}$. Thus, with $0.0144 \mathrm{~m}^{2}$, the required airflow was $0.36 \mathrm{~m} / \mathrm{s}$.

\section{Results and Discussion}

This research was conducted at the State Polytechnic of Malang, Malang city, East Java, Indonesia. The coordinates are: $7^{\circ} 56^{\prime} 44.57^{\prime \prime}$ south latitude and $112^{\circ} 36.53 .20^{\prime \prime}$ east longitude, and an altitude is $499 \mathrm{~m}$ above the sea level. The research was conducted with consumption and without incubator consumption.

\section{Capability and efficiency of heat energy Absorption in the accumulator}

The accumulator absorption capability is shown from the accumulator temperature compared with ambient temperature, shown in Fig. 6 and Fig. 7. From Fig. 7, the accumulator capability shows that accumulator temperature (Tacc) increases along with increasing sunlight intensity $\left(I_{\text {diff }}\right)$ until it reaches $100{ }^{\circ} \mathrm{C}$ at $14: 19$ local

Fig. 6. The accumulator absorption capability with load

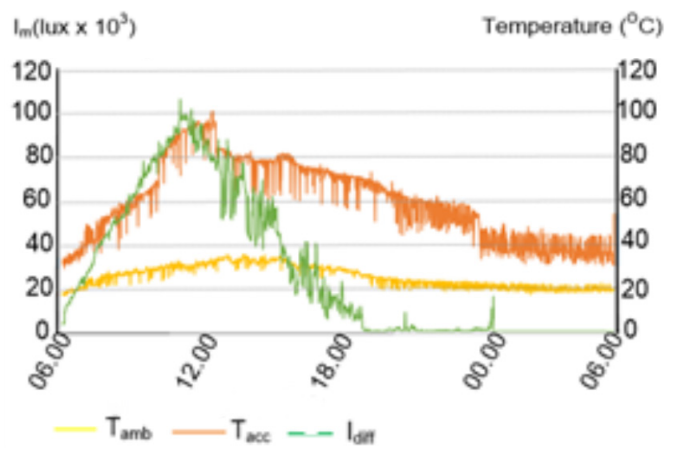


time. The maximum temperature was obtained within 7 hours due to the fluctuating intensity of sunlight.

In Fig. 8 at the same location, the data show relatively high light intensity (intensity maximum 106423 lux). The highest temperature accumulator occurred earlier at 11:35 local time.

Fig. 7. The accumulator absorption capacity without load

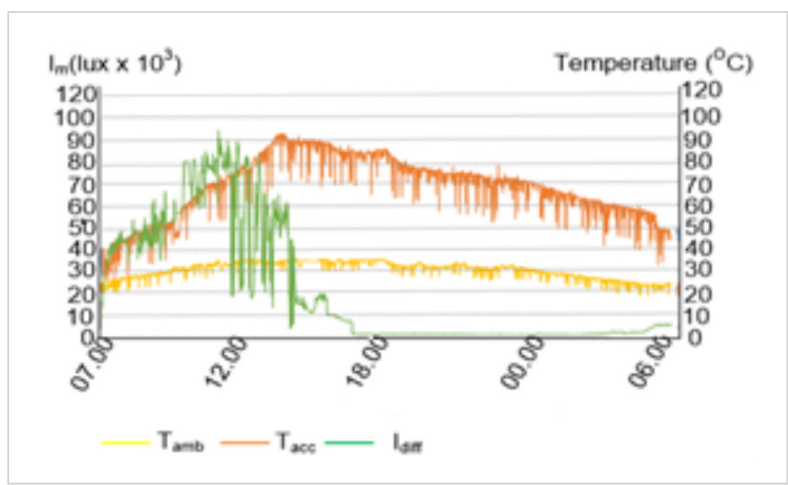

The efficiency of thermal energy absorption could be calculated from the amount of solar energy $\left(E_{\text {diff }}\right)$ from the system started until the array was closed compared with the energy that can be absorbed by an accumulator $\left(E_{A c c}\right)$. Thus, it can be calculated by using equation (3):

$$
E_{A c c}=E_{a}+E_{g}+E_{w}
$$

Table 1. The energy absorbed by an accumulator with load

\begin{tabular}{c|c|c|c} 
Material & $\begin{array}{c}\text { Mass } \\
(\mathrm{Kg})\end{array}$ & $\begin{array}{c}\mathrm{SHC} \\
\left(\mathrm{j} / \mathrm{g}^{\circ} \mathrm{c}\right)\end{array}$ & $\begin{array}{c}\text { Energy } \\
(\mathrm{Kwhh})\end{array}$ \\
\hline Air & $m_{a}=0.98$ & $C_{a}=0.716$ & $E_{a}=0.011$ \\
\hline Galvanize & $m_{g}=48.8$ & $C_{g}=0.46$ & $E_{g}=0.196$ \\
\hline Water & $m_{w}=101.06$ & $C_{w}=4.2$ & $E_{w}=7.47$ \\
\hline \multicolumn{3}{|c|}{ Energy of accumulator } & $E_{\text {Acc }}=7.70$
\end{tabular}

Table 2. The energy absorbed by an accumulator without load

\begin{tabular}{c|c|c|c}
\hline Material & $\begin{array}{c}\text { Mass } \\
(\mathrm{Kg})\end{array}$ & $\begin{array}{c}\mathrm{SHC} \\
\left(\mathrm{j} / \mathrm{g}^{\circ} \mathrm{c}\right)\end{array}$ & $\begin{array}{c}\text { Energy } \\
(\mathrm{Kwhh})\end{array}$ \\
\hline Air & $m_{a}=0.98$ & $C_{a}=0.716$ & $E_{a}=0.007$ \\
\hline Galvanize & $m_{g}=48.8$ & $C_{g}=0.46$ & $E_{g}=0.52$ \\
\hline Water & $m_{w}=101.06$ & $C_{w}=4.2$ & $E_{w}=7.54$ \\
\hline \multicolumn{3}{|c|}{ Energy of accumulator } & $E_{\text {Acc }}=8.07$ \\
\hline
\end{tabular}

The energy that can be absorbed by an accumulator $\left(E_{\text {Acc }}\right)$ is shown in Table 1 and Table 2.

The efficiency of thermal energy absorption with load by direct solar was $57.81 \%$. It was defined by Fig. 8 and equation (4):

$$
\eta_{A c c}=\frac{\int_{06: 00}^{11: 59} m \cdot c \cdot T d t}{\int_{06: 00}^{11: 59} P_{\text {sun }} d t} .100 \%
$$

Fig. 8. Direct solar energy accumulation and accumulator (with load)

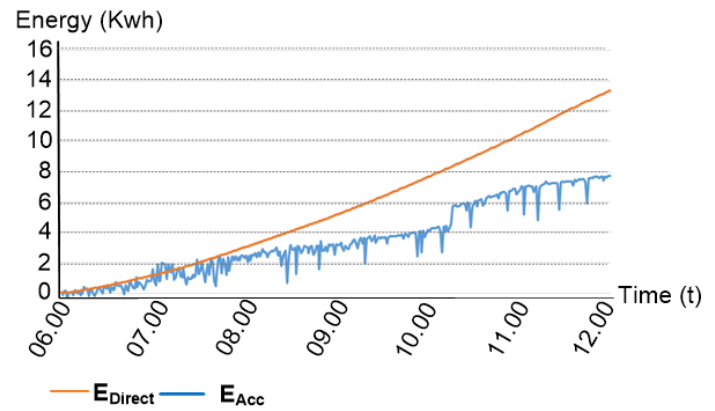

The efficiency of thermal energy absorption with load by solar diffuse was $70.07 \%$. It was defined by Fig. 9 and equation (5):

Fig. 9. Diffuse solar energy accumulation and accumulator (with load)

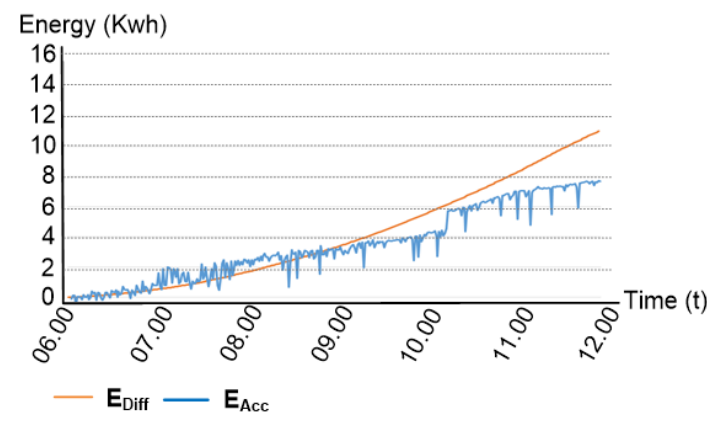

$$
\eta_{A c c}=\frac{\int_{06: 00}^{11: 59} m \cdot c \cdot T d t}{\int_{06: 00}^{11: 59} P_{d i f f} d t} \cdot 100 \%
$$


The efficiency of thermal energy absorption in the accumulator without load by direct solar was $54.11 \%$. It was defined by Fig. 10 and equation (6):

Fig. 10. Direct solar energy accumulation and accumulator (without load)

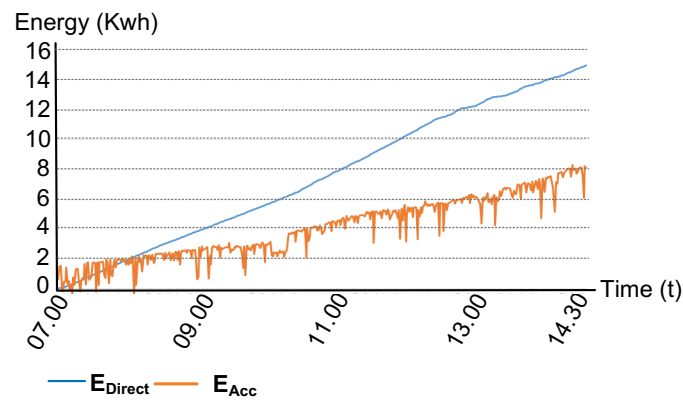

$$
\eta_{A c c}=\frac{\int_{07: 00}^{14: 42} m \cdot c \cdot T}{\int_{07: 00}^{14: 42} P_{\text {sun }} d t} \cdot 100 \%
$$

In addition, the efficiency of thermal energy absorption in the accumulator without load by solar diffuse was 60.44 $\%$. It is defined by Fig. 11 and equation (7):

Fig. 11. Diffuse solar energy accumulation and accumulator (without load)

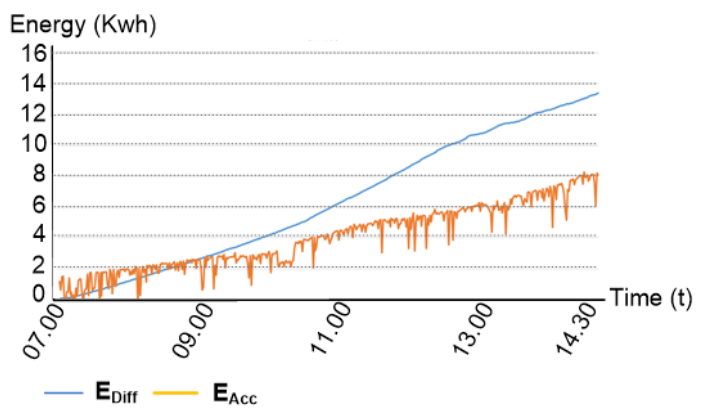

$$
\eta_{\text {Acc }}=\frac{\int_{07: 00}^{14: 42} m . c . T}{\int_{07: 00}^{14: 42} P_{d i f f} d t} .100 \%
$$

Thus, the efficiency average of thermal energy absorption in the accumulator is shown in Table 3.

Table 3. Efficiency of thermal energy absorption

\begin{tabular}{c|c|c}
\hline Accumulator & Direct Solar & Solar diffuse \\
\hline With load & $\eta_{\text {Acc }}=57.81 \%$ & $\eta_{\text {Acc }}=70.07 \%$ \\
\hline Without load & $\eta_{\text {Acc }}=54.11 \%$ & $\eta_{\text {Acc }}=60.44 \%$ \\
\hline
\end{tabular}

The efficiency can be increased by maximizing control of the array; thus, the absorbed energy will be maximally trapped.

\section{Capability of water as storage medium and energy source}

The capacity of water energy storage can be seen from the effectiveness of water in supplying heat energy when there is no solar energy, both during the day and night.

Fig. 12. Capability of storage and water supply

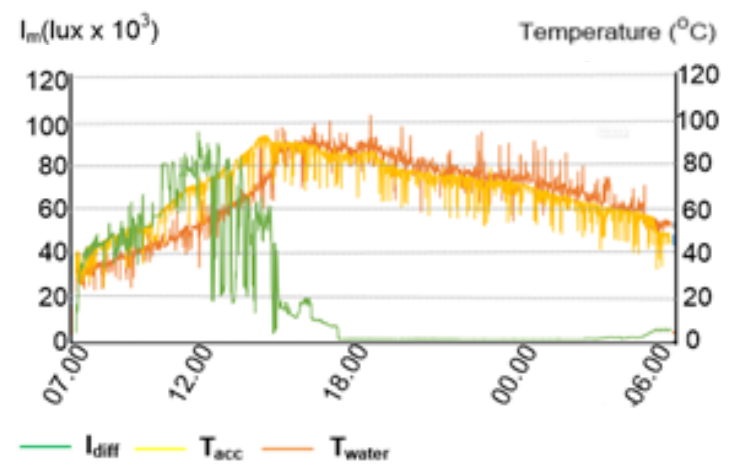

As shown in Fig. 12, when the light intensity $\left(\mathrm{I}_{\text {diff }}\right)$ disappeared at 17:02 local time, the temperature in the accumulator did not decrease significantly. The decrease in accumulator temperature was proportional to water temperature decrease $\left(T_{\text {water }}\right)$.

The water temperature decreased within 15 hours and 27 minutes to $35^{\circ} \mathrm{C}$. Therefore, the average decrease in water temperature was $0.03^{\circ} \mathrm{C} / \mathrm{min}$. The water capability was acceptable for keeping the heating temperature. Thus, water was suitable for heat storage media. 


\section{Control optimizer energy accumulator}

Controls were performed on the array movement in order to maintain the thermal energy stored in the accumulator.

In Fig. 13, the controller showed that the array would open at the minimum temperature. The controller served to capture solar thermal energy. The control operated when the accumulator temperature $\left(\mathrm{T}_{\text {acc }}\right)$ reached $100^{\circ} \mathrm{C}$; then the array closed. This algorithm served to maintain the amount of heat energy in the accumulator.

Fig. 13. Control optimizer energy accumulator

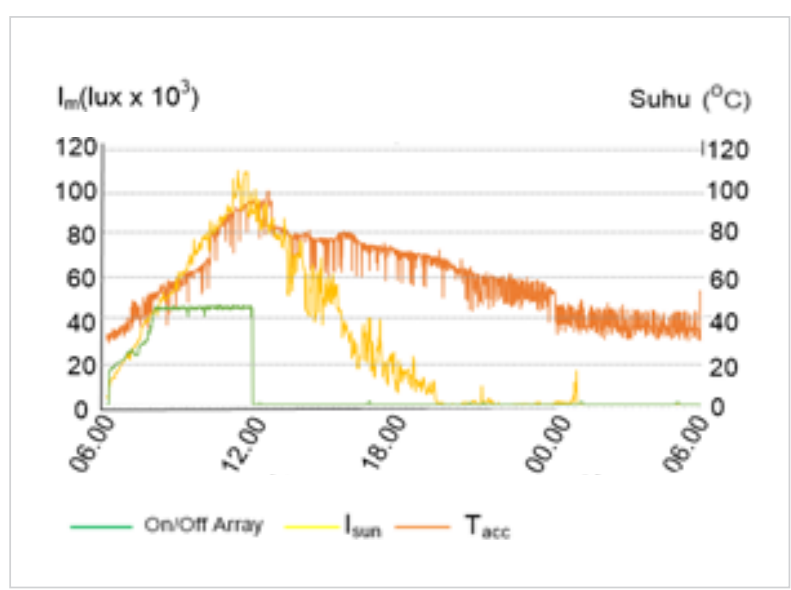

\section{Capability of heat accumulator energy aupply to the hatcher}

From Fig.14, it is shown that the accumulator hatching system operation started at 06:00, when the accumulator temperature was $22{ }^{\circ} \mathrm{C}$ and used an electric heater. At 07:55 local time when the accumulator temperature $\left(T_{\text {acc }}\right)$ reached $45^{\circ} \mathrm{C}$, the heater source was changed to the accumulator and used throughout the day until 23:57 local time. The accumulator was able to supply the hatcher for 16 hours and 2 minutes.

In Fig. 10, it is shown that to supply the hatcher for approximately 16 hours 2 minutes, it took as much as 7.70 kWh of heat energy.

The calculation results found that the average consumption per hour was $0.47 \mathrm{kWh} / \mathrm{h}$. Therefore, to supply the hatcher for approximately 24 hours, 11.4 kWh or 41066 $\mathrm{kJ}$ of heat energy was needed.
From equation 8, it is known that the amount of energy was directly affected by specific heat capacity, mass, and temperature differences. Of the three parameters which allowed being increased was the mass.

Therefore, to increase the heat energy to supply the hatcher for approximately 24 hours, the addition of water required was $130.36 \mathrm{~kg}$ or $130.36 \mathrm{~L}$. It was calculated by equation (8).

$$
M w=\frac{\int_{t 0}^{t} P_{a c c} d t}{C w \cdot \Delta T}
$$

Fig. 14. The accumulator supply capability

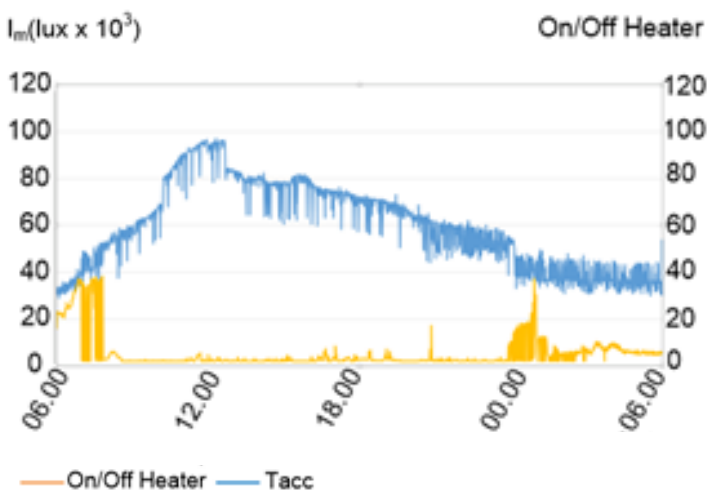

\section{Electrical energy consumption}

In this system, electrical energy was used to control the system and the electric heater.

The electrical energy used to control it could be seen when the system used an accumulator as a heat energy supply. The system started from 07:55 to 23:57 local time or 16 hours 2 minutes.

In order to supply a hatcher for 16 hours 2 minutes, it took 969.6 Wh of heat energy, and the percentage of electrical energy used for control compared with the hatcher energy requirement was $24.95 \%$, as shown in equation (9) and equation (10). 


$$
E_{\text {Egg }}=\int_{07: 55}^{23: 57} P_{\text {egg }} d t
$$

$$
\eta_{C E}=\frac{\int_{07: 55}^{23: 59} P_{\text {Electrical }} d t}{\int_{07: 55}^{23: 59} P_{\text {egg }} d t} .100 \%
$$

The electrical energy consumption for the electric heater in this system started from 06:00 to 07:55 local time ( 2 hours and 55 minutes), as shown in Fig. 16.

Fig. 15. Electrical energy for about 16 hours 2 minutes

Energy (Wh)

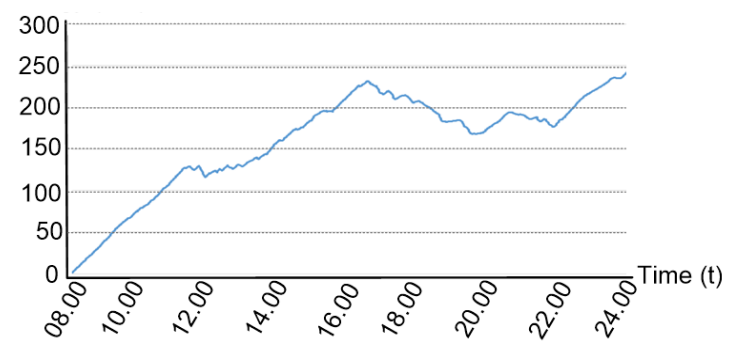

Fig. 16. Electrical energy consumption

$$
\text { Energy (Wh) }
$$

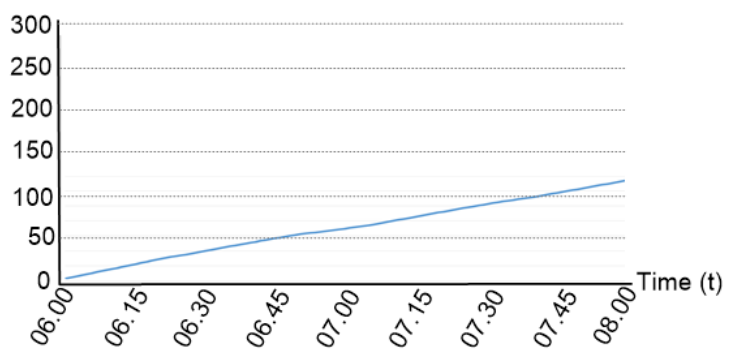

Thus, the electrical energy consumption for this system is shown in Table 4.

Table 4. Electrical energy consumption

\begin{tabular}{c|c|c}
\hline \multicolumn{1}{c|}{ Parameter } & $\begin{array}{c}\text { Energy } \\
\text { consumption } \\
(\text { Wh })\end{array}$ & $\begin{array}{c}\text { Presentation } \\
\text { consumption }\end{array}$ \\
\hline $\begin{array}{l}\text { Electrical energy to } \\
\text { control the system }\end{array}$ & $E_{C E}=242$ & $\eta_{C E}=24.95 \%$ \\
\hline $\begin{array}{l}\text { Electrical energy for } \\
\text { the electrical heater }\end{array}$ & $E_{E C}=133.96$ & $\eta_{E C}=12.28 \%$ \\
& & \\
\hline
\end{tabular}

\section{Conclusions}

In this research, the accumulator obtained and stored solar thermal energy for the requirement in the evening and night. The solar thermal accumulator capability to store thermal energy was up to $7.07 \mathrm{kWh}$. The accumulator could be used as a heat supply incubator for 16 hours and 2 minutes with an average absorption efficiency of $54-58 \%$ by direct solar and $60-70 \%$ by solar diffuse. In addition, the electrical energy consumption for control was $24.95 \%$, and the electrical heater was $12.28 \%$. Therefore, this technology can decrease electrical (fossil) consumption and reduce environmental pollution caused by fossil energy to electrical energy.

\section{Acknowledgements}

Deep gratitude was expressed to Indonesian Ministry of Research Technology and Higher Education for the funding provided to this research, as well as to Malang State Polytechnic for its support. 


\section{References}

Bhowmik, Himangshu, and Ruhul Amin. (2017) Efficiency improvement of flat plate solar collector using reflector. Energy Reports 3: 119-123. https://doi.org/10.1016/j.egyr.2017.08.002

French, N. A. (1997) Modeling incubation temperature: The effects of incubator design, embryonic development, and egg size. Poultry Science 76.1: 124-133. https://doi.org/10.1093/ ps/76.1.124

Kuye, S. I., Adekunle, N. O., Adetunji, O. R., and Olaleye, D. O. (2008). Design and Construction of Solar Incubator. College of Natural Sciences Proceedings, 87-96.

Lourens, A., Roos Molenaar, Henry van den Brand, M. J. W. Heetkamp, Ron Meijerhof, and Bas Kemp. (2006) Effect of egg size on heat production and the transition of energy from egg to hatchling. Poultry Science 85, no. 4: 770-776 https://doi.org/10.1093/ ps/85.4.770

Nasruddin, M. N. (2007) Determination of Temperature in Egg Hatching Based on Microprocessor. Journal of MIPA 1: 30-33

Okpagu, P. E., and A. W. Nwosu. (2016) Development and Temperature Control of Smart Egg Incubator System for Various Types of Egg. European Journal of Engineering and Technology Vol 4.2.

Ramli, Mohd Badli, et al. (2015) Egg hatching incubator using conveyor rotation system. Procedia Manufacturing 2: 527-531. https://doi.org/10.1016/j.promfg.2015.07.091

Republika, (2014) Indonesia Electricity Production Still Rely on Fossil Energy, interview with Minister of Energy and Mineral Re- sources Susilo Siswoutomo. 2020125 MW currently 50 MW, coal as the backbone of electric energy other than fuel, 01 October

Setiawan, B. (2017). Heat Regulator for Hybrid Hatch Machine with Buck PID Method. SENTIA 2017, 79(3).

Setiawan, B., Damayanti, A. M., Murdani, A., Habibi, I. I. A., and Wakidah, R. N. (2018, April). Fixed Nadir Focus Concentrated Solar Power Applying Reflective Array Tracking Method. In IOP Conference Series: Materials Science and Engineering (Vol. 336, No. 1, p. 012002). IOP Publishing. https://doi.org/10.1088/1757899X/336/1/012002

Setiawan, B., Wakidah, R. N., and Yulianto, Y. (2020). Reflective Array Solar Water Heater for Milk Pasteurization. Environmental Research, Engineering and Management, 76(4), 131-137. https://doi.org/10.5755/j01.erem.76.4.24411

Setiawan, B., Wakidah, R. N., Edy, P. R., Maulidia, D. A., Yulianto, Y., and Widjanarko, W. (2018). Empirical base solar reflective array accumulator design simulator. In MATEC Web of Conferences (Vol. 197, p. 11017). EDP Sciences https://doi. org/10.1051/matecconf/201819711017

Shoeibi, S., Rahbar, N., Esfahlani, A. A., and Kargarsharifabad, $\mathrm{H}$. (2020). Application of simultaneous thermoelectric cooling and heating to improve the performance of a solar still: An experimental study and exergy analysis. Applied Energy, 263, 114581 https://doi.org/10.1016/j.apenergy.2020.114581

Syah, Bastaman. (2012) Design of Temperature and Humidity Control System of hatcher-Based PLC (Programmable Logic Controller).Electrician 2.1 (2012): 25-32. 